\title{
Southern Saskatchewan Ticagrelor Registry experience
}

\author{
This article was published in the following Dove Press journal: \\ Patient Preference and Adherence \\ 16 October 2014 \\ Number of times this article has been viewed
}

\author{
Payam Dehghani' \\ Varun Chopra' \\ Ali Bell ${ }^{2}$ \\ Sheila Kelly' \\ Lori Zulyniak ${ }^{2}$ \\ Jeff Booker' \\ Rodney Zimmermann' \\ William Semchuk ${ }^{2}$ \\ Asim N Cheema ${ }^{3}$ \\ Andrea J Lavoie'
}

'Prairie Vascular Research Network, University of Saskatchewan, Regina, SK, ${ }^{2}$ Regina Qu'Appelle Health Region, Regina, SK, ${ }^{3}$ St Michael's Hospital, University of Toronto, Toronto,

ON, Canada
Correspondence: Payam Dehghani Prairie Vascular Research Network (PVRN), Unit 3A, Interventional Cardiology Research Office, Regina General Hospital I440 I4th Avenue, Regina, SK S4P 0W5, Canada

Tel +30678 I 7944

Fax +306 78I 6997

Email pdehghani@mac.com
Background: As ticagrelor enters into clinical use for acute coronary syndrome, it is important to understand patient/physician behavior in terms of appropriate use, adherence, and event rates. Methods: The Southern Saskatchewan Ticagrelor Registry is a prospective, observational, multicenter cohort study that identifies consecutive patients started on ticagrelor. We aimed to evaluate both on- and off-label use, identify characteristics of patients who prematurely stop ticagrelor, and describe patient/physician behavior contributing to inappropriate stoppage of this medication.

Results: From April 2012 to September 2013, 227 patients were initiated on ticagrelor, with a mean age of $62.2 \pm 12.1$ years. The participants were $66 \%$ men and had a mean follow up of $157.4 \pm 111.7$ days. Seventy-four patients (32.4\%) had off-label indications. Forty-seven patients (20.7\%) prematurely stopped ticagrelor and were more likely to be older, women, nonwhite, present with shock, and complain of dyspnea. Twenty-six of the 47 patients stopped ticagrelor inappropriately because of patient nonadherence (18 patients) and physician advice (eight patients). A composite outcome event of death from vascular causes, myocardial infarction, or stroke occurred in $8.8 \%$ of the entire cohort and was more likely to occur in those older then 65 years, those presenting with cardiogenic shock, and those who prematurely stopped ticagrelor.

Conclusion: In this real-world registry of patients started on ticagrelor, a third have off-label indications and a fifth prematurely stop the medication. Premature discontinuation was an independent predictor of major life-threatening bleeding and increased composite event rate of death from vascular causes, myocardial infarction, or stroke.

Keywords: ticagrelor, acute coronary syndrome, registry, adherence, compliance, antiplatelets

\section{Introduction}

Ticagrelor $\left(\right.$ Brilinta $\left.^{\circledR}\right)$ is an oral antiplatelet that was approved in Canada in May 2011 for secondary prevention in patients with acute coronary syndrome (ACS) when coadministered with low-maintenance-dose aspirin (75-150 mg). This was based on a multicenter, double-blind, randomized trial, the Study of Platelet Inhibition and Patient Outcomes (PLATO), in which ticagrelor was compared with clopidogrel. In patients who have ACS, treatment with ticagrelor as compared with clopidogrel significantly reduced the rate of death from vascular causes, myocardial infarction, or stroke without an increase in the rate of overall major bleeding. ${ }^{1}$ This resulted in ticagrelor's adoption into the guidelines published by the Cardiovascular Society, the European Society of Cardiology, the American College of Cardiology Foundation, and the American Heart Association..$^{2-6}$ However, gaps in the adoption of novel therapies for ACSs are well documented. ${ }^{7}$ Primary nonadherence rates to the thienopyridine clopidogrel have been reported to vary between $10 \%$ and $30 \%$ in situations in which that agent was 
covered by provincial drug plans, with median time from hospital discharge to first prescription fill being 4-5 days in two Canadian studies. ${ }^{8,9}$ Secondary adherence rates to most chronic medications used in the care of cardiovascular therapeutics hover at approximately $50 \%-70 \%$ at 1 year in situations in which agents are covered by government payers. ${ }^{10}$

As ticagrelor enters into clinical use, it is important to understand patient and physician behavior in terms of adherence, counseling, and reasons for changing and/or stopping the medication. An established method of evaluating adoption of new agents in the community is longitudinal clinical registries that provide information on the effectiveness and safety in "real-world" patient populations. The aim of this study was to evaluate the number and characteristics of patients who prematurely stop ticagrelor, to describe patient and physician behavior that contributes to inappropriate stoppage of this medication, and to determine the event rate and safety endpoints of this real-world cohort.

\section{Methods}

The Southern Saskatchewan Ticagrelor Registry is a prospective, observational, multicenter cohort study involving one center with percutaneous coronary intervention (PCI) capability and nine non-PCI facilities in the Regina Qu'Appelle Health Region (RQHR), Saskatchewan, Canada. The drawing population of this region is roughly 500,000 patients. Consecutive patients beginning ticagrelor at the PCI facility were identified through the Department of Pharmacy computer system, Centricity ${ }^{\circledR}$. All patients initiated on ticagrelor who consented were enrolled in a registry, and clinical outcomes were prospectively collected. PLATO inclusion and exclusion criteria were used to assess the appropriate use of this medication. ${ }^{1}$ Interventional cardiologists prescribed ticagrelor at their discretion according to best clinical practice. Ethical approval was obtained by the RQHR Ethics Board before patient recruitment. An unrestricted educational grant from Prairie Cardiac Foundation was used to set up the database for this registry. All data were retrieved, stored, and analyzed at the Regina General Hospital.

Patient demographic characteristics, relevant medical history, hospitalization, in-hospital therapy, laboratory tests, and in-hospital patient outcomes were collected. Follow-up was performed at 1,6 , and 12 months by telephone interview or personal contact. Data on bleeding events, patient demographics, medical history, re-hospital therapy, in-hospital therapy, timing of care delivery, and in-hospital patient outcomes were collected. A 30-day follow-up period was adopted whenever possible; however, some patients had a 6-month interview by telephone or personal contact. If there was a clinical event, the patient's medical records were obtained from the hospital and reviewed.

\section{Introduction of ticagrelor to Saskatchewan}

After publication of the PLATO trial, ticagrelor was granted a Health Canada indication (May 30, 2011) for secondary prevention of atherothrombotic events in patients with ACS who are to be managed medically and in those who are to be managed with PCI and/or coronary artery bypass surgery (CABG). The Canadian Drug Evaluating Committee final recommendation was provided on December 16, 2011, and indicated that ticagrelor should not be listed on Canadian Provincial Drug Plan formularies at the submitted price. Within the RQHR, ticagrelor was added to the Hospital Formulary on March 20, 2012, but was restricted to patients who suffered stent thrombosis while receiving clopidogrel in the preceding 28 days. Effective April 1, 2012, ticagrelor was also added to the Saskatchewan Formulary under Exception Drug Status, mirroring the RQHR Hospital Formulary. After these additions, the Brillinta Continuity of Care Program was made available through AstraZeneca across Canada by issuing an access card to all patients. This ensured that the price of ticagrelor was not more than clopidogrel in the outpatient setting. In September 2012, the RQHR Hospital Formulary expanded the criteria for ticagrelor use to include all ACS patients. As of November 1, 2012, the Saskatchewan Provincial Drug Plan Formulary revised and expanded the Exception Drug Status criteria for ticagrelor. All patients studied received the ticagrelor access card.

\section{Definitions}

On-label indications for ticagrelor were defined as those who did not have exclusion criteria and who met inclusion criteria as set out by the PLATO trial. Patients were required to be hospitalized for an ACS, with or without ST-segment elevation, with an onset of symptoms during the previous 24 hours. For patients who had an ACS without ST segment elevation, at least two of the following three criteria had to be met: ST-segment changes on electrocardiography, indicating ischemia; a positive test of a biomarker, indicating myocardial necrosis; or one of several risk factors (age of 60 years or older; previous myocardial infarction or $\mathrm{CABG}$; coronary artery disease with stenosis of $50 \%$ or higher in at least two vessels; previous ischemic stroke, transient ischemic attack, carotid stenosis of at least $50 \%$, or cerebral revascularization; diabetes mellitus; peripheral arterial disease; or chronic 
renal dysfunction, defined as creatinine clearance lower than $60 \mathrm{~mL}$ per minute per $1.73 \mathrm{~m}^{2}$ of body surface area). For patients who had an ACS with ST-segment elevation, the following two inclusion criteria had to be met: persistent STsegment elevation of at least $0.1 \mathrm{mV}$ in at least two contiguous leads or a new left bundle branch block, and the intention to perform primary PCI. Major exclusion criteria were any contraindication against the use of clopidogrel, fibrinolytic therapy within 24 hours before randomization, a need for oral anticoagulation therapy, an increased risk for bradycardia, and concomitant therapy with a strong cytochrome P-450 3A inhibitor or inducer.

Off-label use for ticagrelor was defined as those who did not meet inclusion and/or who met exclusion criteria. Region was defined as localities within 1 hour driving distance to the primary PCI center. Race was identified by self-declaration as white or nonwhite, a method used in other studies in which the effect of ethnicity was analyzed. ${ }^{11}$ Patient nonadherence was defined as inappropriately stopping ticagrelor without seeking medical advice. All charts of patients who stopped taking ticagrelor were reviewed to determine whether physician advice to stop/change ticagrelor was appropriate or inappropriate, using society guidelines. Death from vascular causes was defined as death from cardiovascular causes or cerebrovascular causes and any death without another known cause. Myocardial infarction was defined in accordance with the universal definition proposed in 2007..$^{12}$ The Academic Research Consortium criteria were used to evaluate stent thrombosis. ${ }^{13}$ Stroke was defined as focal loss of neurologic function caused by an ischemic or hemorrhagic event, with residual symptoms lasting at least 24 hours or leading to death. PLATO definitions were used for all bleeding endpoints. Major life-threatening bleeding was defined as fatal bleeding, intracranial bleeding, intrapericardial bleeding with cardiac tamponade, hypovolemic shock or severe hypotension resulting from bleeding and requiring vasopressors or surgery, a decline in the hemoglobin level of $5.0 \mathrm{~g} / \mathrm{dL}$ or more, or the need for transfusion of at least 4 units of red cells. Other major bleeding was defined as bleeding that led to clinically significant disability (eg, intraocular bleeding with permanent vision loss) or bleeding either associated with a drop in the hemoglobin level of at least $3.0 \mathrm{~g} / \mathrm{dL}$ but less than $5.0 \mathrm{~g} / \mathrm{dL}$ or requiring transfusion of two to three units of red cells. Minor bleeding was defined as any bleeding requiring medical intervention but not meeting the criteria for major bleeding. Shock was defined as presenting with hemodynamic instability and/or requiring intraaortic balloon pump.

\section{Statistical analysis}

Frequency distributions were used to describe data that were categorical in nature. Inferential analysis of this data took the form of chi-square tests. Odds ratios were used as an estimate of effect size and standardized residuals examined to determine which cells were the major contributors to observed differences. Continuous data were examined for their suitability for parametric analysis. Fisher's skewness coefficient was used to determine significant departures from normality. Means and standard deviations describe data that were not significantly skewed and medians and interquartile ranges for data that did not meet the assumptions of parametric testing. Statistical significance was set at $P<0.05$ for all analyses.

A forced entry logistic regression analysis was used to predict the occurrence of adverse target events using variables that were shown from the chi-square analyses to have a significant effect on the frequency of a target event: age older than 65 years, presence of shock, and/or no longer being on ticagrelor.

\section{Results}

Between April 12 and September 1, 2013, 248 patients in RQHR were prescribed ticagrelor for their ACS event. Twenty-one patients were not included in the registry, as they were either enrolled in A 30 Day Study to Evaluate Efficacy and Safety of Pre-hospital vs In-hospital Initiation of Ticagrelor Therapy in STEMI Patients Planned for Percutaneous Coronary Intervention (PCI) (ATLANTIC) trial $(\mathrm{n}=18)^{14}$ or were already receiving the medication started in another province $(n=3)$. Therefore, 227 patients $(66 \%$ men) with a mean age of $62.2 \pm 12.1$ years were included in the analysis. Although $100 \%$ of patients who were still alive at 4 weeks had a 4-week follow-up, the mean follow-up of the entire cohort was $157.4 \pm 111.7$ days (median, 138.0 days; interquartile range, 73.5-234.2 days), whereas the mean follow-up of the group that stopped ticagrelor was $61.2 \pm 96.5$ days (median, 21.0 days; interquartile range, $4.0-82.0$ days).

\section{Off-label usage}

Seventy-four of the 227 patients (32.6\%) who took ticagrelor had an off-label PLATO indication. Although close to half the cohort presented with ST-segment elevation myocardial infarction (STEMI), 19\% did not meet PLATO indications for use of ticagrelor, and $17 \%$ would have been excluded using the PLATO criteria. The most common cause of exclusion was initiation of ticagrelor within 24 hours of fibrinolytic therapy in 32 patients and concomitant use of 
warfarin in another 5 patients. The most common cause of not meeting PLATO inclusion criteria was angina without high-risk features in 39 patients.

\section{Patient adherence and physician behavior}

Forty-seven patients (20.7\%) prematurely stopped taking ticagrelor and, compared with those continuing with ticagrelor, were more likely to be older, women, and nonwhite and to have prior PCI or CABG, present with shock, and complain of dyspnea within the first 4 weeks of starting the medication (Table 1). Of these 47 patients, 18 patients stopped ticagrelor without any input from their cardiologists (three because of dyspnea, ten for reasons unknown, one because of a lack of financial coverage, and four because of coronary artery bypass surgery) with a nonadherence rate of $8.0 \%$ (Figure 1 ). Of the remaining 29 patients, eight were switched by their cardiologists to clopidogrel for reasons not consistent with guideline recommendations (four because of nonlimiting dyspnea, one because of surgical revascularization and fear of excessive bleeding, and three with no reason specified; Figure 1). Therefore, 26 of the 47 patients stopped ticagrelor inappropriately because of patient nonadherence (18 patients) and physician advice (eight patients). The remaining 21 patients stopped ticagrelor or switched to clopidogrel for reasons judged by the investigator to be a result of medication (three had severe dyspnea, five had a significant bleeding event, two had symptomatic ventricular pauses longer than 3 seconds that resolved when switching to clopidogrel, five had coverage for clopidogrel but not ticagrelor, and six developed an indication for Warfarin postpresentation). All patients who had no coverage were of indigenous origin and described themselves as nonwhite.

\section{Outcome}

Twenty events $(8.8 \%$ of the entire cohort) were noted in this group (Table 2). Cardiogenic shock on presentation was predictive of having an event in our registry, whereas age younger than 65 years, off-label use of ticagrelor, and

Table I Characteristics of patients who continued or prematurely stopped ticagrelor

\begin{tabular}{|c|c|c|c|c|}
\hline Characteristics & $\begin{array}{l}\text { Ticagrelor, all } \\
(n=227)\end{array}$ & $\begin{array}{l}\text { Ongoing ticagrelor } \\
(n=\mid 80)\end{array}$ & $\begin{array}{l}\text { Stopped } \\
\text { ticagrelor }(n=47)\end{array}$ & $P$-value* \\
\hline \multicolumn{5}{|l|}{ Baseline characteristics } \\
\hline Age, years & $62.2 \pm 12.1$ & $62.1 \pm 12.5$ & $67.4 \pm 11.4$ & $<0.01$ \\
\hline Age, $>65$ years & $98(43.2)$ & $72(40.0)$ & $26(55.3)$ & NS \\
\hline Male, $n$ & $149(65.6)$ & $124(68.9)$ & $25(53.1)$ & $<0.05$ \\
\hline Body mass index, $\mathrm{kg} / \mathrm{m}^{2}$ & $30.4 \pm 5.8$ & $30.2 \pm 5.4$ & $31.5 \pm 7.2$ & NS \\
\hline Hypertension & II 17 (5I.5) & 88 (48.9) & $29(61.7)$ & NS \\
\hline Diabetes & $69(30.4)$ & $55(30.6)$ & $14(29.8)$ & NS \\
\hline Dyslipidemia & $107(47.1)$ & 84 (46.9) & $23(48.9)$ & NS \\
\hline Prior $\mathrm{PCl}$ & $42(18.5)$ & $28(I 5.6)$ & I4 (29.8) & $<0.05$ \\
\hline Prior CABG & $20(8.8)$ & II (6.1) & $9(19.1)$ & $<0.005$ \\
\hline Nonwhite & $46(20)$ & $26(14)$ & $20(43)$ & $<0.005$ \\
\hline From Region & $145(63.9)$ & $110(61.1)$ & $35(74.5)$ & NS \\
\hline \multicolumn{5}{|l|}{ Presentation } \\
\hline STEMI & $104(45.6)$ & $82(45.6)$ & $22(46.8)$ & NS \\
\hline NSTEMI & $80(35.2)$ & $62(34.4)$ & $18(38.3)$ & NS \\
\hline Shock & $14(6.2)$ & $8(4.4)$ & $6(12.2)$ & $<0.005$ \\
\hline \multicolumn{5}{|c|}{ Off-Ion-label use according to PLATO } \\
\hline Did not meet inclusion & $44(19.4)$ & $36(20.0)$ & $8(I 7.0)$ & NS \\
\hline Met PLATO exclusion & $39(17.2)$ & $29(16.1)$ & $10(21.3)$ & NS \\
\hline Off-label use & $74(32.4)$ & $60(33.3)$ & $14(29.8)$ & NS \\
\hline \multicolumn{5}{|l|}{ Treatment } \\
\hline Eventually required CABG & $23(10.1)$ & $18(10.0)$ & $5(10.6)$ & NS \\
\hline Medical therapy & $18(7.9)$ & II (6.I) & $7(14.9)$ & $<0.05$ \\
\hline $\mathrm{PCl}$ & $209(92.1)$ & $169(93.9)$ & $40(85.1)$ & $<0.05$ \\
\hline \multicolumn{5}{|c|}{ Follow-up questionnaire within the first 4 weeks } \\
\hline Dyspnea & $47(20.7)$ & $29(16.1)$ & $18(38.3)$ & $<0.005$ \\
\hline
\end{tabular}

Notes: *Compared with ticagrelor ongoing therapy group. Values are $\mathrm{n}(\%)$ or mean \pm standard deviation. From Region, within I hour driving distance to the PCl facility; nonwhite, self-identified as non-Caucasian. Off-label use for ticagrelor was defined as those who did not meet inclusion and/or who met exclusion criteria.

Abbreviations: NS, not significant; PCI, percutaneous coronary interventions; CABG, coronary artery bypass surgery; STEMI, ST-segment elevation myocardial infarction; NSTEMI, non-ST-segment elevation myocardial infarction; PLATO, Study of Platelet Inhibition and Patient Outcomes. 


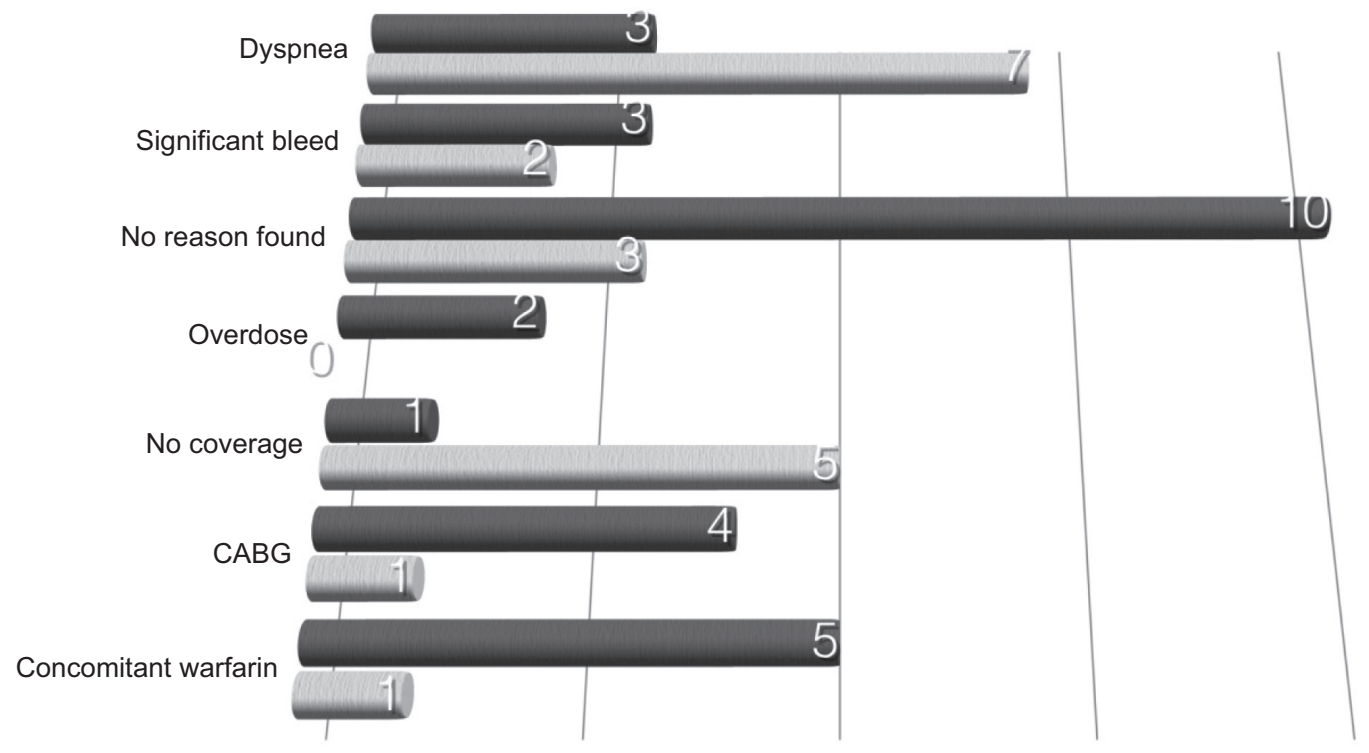

Figure I Cited reasons for those who stopped taking ticagrelor.

Abbreviation: $C A B G$, coronary artery bypass surgery.

continuing with ticagrelor were associated with decreased events (Figure 2). There were two patients with definite stent thrombosis, one of whom had stopped taking ticagrelor 3 weeks after initiation, and the other thrombotic episode was determined to be a result of mechanical issues with stent deployment in a degenerative vein graft. In multivariate analysis, age older than 65 years, presenting with cardiogenic shock, and prematurely stopping ticagrelor were strong predictors of having an event when compared with those who continued with the medication (Figure 3).

\section{Safety}

Compared with those continuing with ticagrelor, a significantly higher number of patients in the group that stopped ticagrelor had a bleeding event $(10.3 \%$ versus $21.3 \%$; $P<0.05)$. Although there was no difference in the incidence of major or minor bleeding events between the two groups, patients with major life-threatening bleeding were more frequent in those who prematurely stopped taking ticagrelor
$(1.7 \%$ versus $6.4 \% ; P<0.05)$. Patients who met PLATO exclusion criteria did not have more evidence of bleeding episodes compared with those who did not have exclusion criteria ( $10.3 \%$ versus $12.8 \%$; $P=0.1$; Table 3$)$.

\section{Discussion}

In this first exclusive description of ticagrelor use in a real-world setting, the novel findings of this registry can be summarized as follows: up to a third of indications for use of ticagrelor are considered off-label, approximately $20 \%$ of patients started on ticagrelor are no longer taking it after a median follow-up of 21 days because of a combination of patient nonadherence and physician behavior, and prematurely stopping ticagrelor is an independent predictor of death from vascular causes, myocardial infarction, or stroke.

It is well-established that ticagrelor provides both a morbidity and mortality benefit compared with clopidogrel for patients with ACSs. Further publications from the PLATO trial have reinforced this in different subsets of

Table 2 Events in Southern Saskatchewan Ticagrelor Registry

\begin{tabular}{lllll}
\hline Events & Entire cohort & Ongoing ticagrelor & Stopped ticagrelor & $P$-value* \\
\hline Composite endpoints & $20(8.8)$ & $9(5.0)$ & II $(23.4)$ & $<0.00 I$ \\
Myocardial infarction & $9(4.0)$ & $6(3.3)$ & $3(6.4)$ & $\mathrm{NS}$ \\
Death from vascular causes & $7(3.1)$ & $2(1.1)$ & $5(10.6)$ & $<0.005^{* *}$ \\
Stroke & $4(1.8)$ & $1(0.6)$ & $3(6.4)$ & $<0.05^{* *}$ \\
\hline
\end{tabular}

Notes: *Compared with ticagrelor ongoing therapy group. **Fisher's exact test used to correct for small cell sizes. Composite endpoints include myocardial infarction, death from vascular cause, and/or stroke. Values are $\mathrm{n}(\%)$.

Abbreviation: NS, not significant. 




Figure 2 Univariate predictors of having an event in the registry.

Notes: Presenting with shock and premature stopping of ticagrelor were predictive of having an event in our registry. Age younger than 65 years and off-label use of ticagrelor were associated with decreased events. "Within region" means within I hour driving distance to the percutaneous coronary intervention facility. Off-label use for ticagrelor was defined as those who did not meet inclusion and/or who met exclusion criteria.

Abbreviations: STEMI, ST-segment elevation myocardial infarction; NSTEMI, non-ST-segment elevation myocardial infarction; CABG, coronary artery bypass surgery; $\mathrm{OR}$, odds ratio; $\mathrm{Cl}$, confidence interval.

the population, including those for whom an early invasive strategy is planned, ${ }^{15}$ those intended for noninvasive management, ${ }^{16}$ patients with renal dysfunction, ${ }^{17}$ patients with diabetes, ${ }^{18}$ those older than 75 years, ${ }^{19}$ those with previous stroke, ${ }^{20}$ those who underwent $\mathrm{CABG}$ as a revascularization strategy, ${ }^{21}$ and those with dysfunctional Cyp2c19 allele. ${ }^{22}$ This cardiovascular benefit is effective in both first and recurrent cardiovascular events ${ }^{23}$ and has also proven to have superior cost-effectiveness ${ }^{24}$ to clopidogrel.

Although the efficacy is well-established in the above subgroups, there are sparse data on its effectiveness in realworld settings. In the recently published Greek Antiplatelet (GRAPE) Registry, clopidogrel was still the most commonly used antiplatelet agent for STEMI/NSTEMI/unstable angina at discharge, with ticagrelor coming in as a close second. ${ }^{25}$
The rate of off-label use of ticagrelor was higher in this study, at $32 \%$ compared with $21 \%$ in the GRAPE Registry. The larger number in this series can likely be explained by the drawing population of the RQHR in which one-third of the patient population comes from a non-PCI facility and has already received thrombolytic therapy. The provincial regulatory body in this province does not discriminate use of ticagrelor for patients who have received thrombolytic therapy within 24 hours but, rather, endorses its use for patients with highrisk coronary anatomy. The current data are concordant with other published, but admittedly few, registry data indicating that the use of ticagrelor in this setting is not associated with increased cardiac events. ${ }^{26}$ Another noteworthy finding was the observation that declaring oneself as nonwhite predicted premature discontinuation of ticagrelor. Although economic

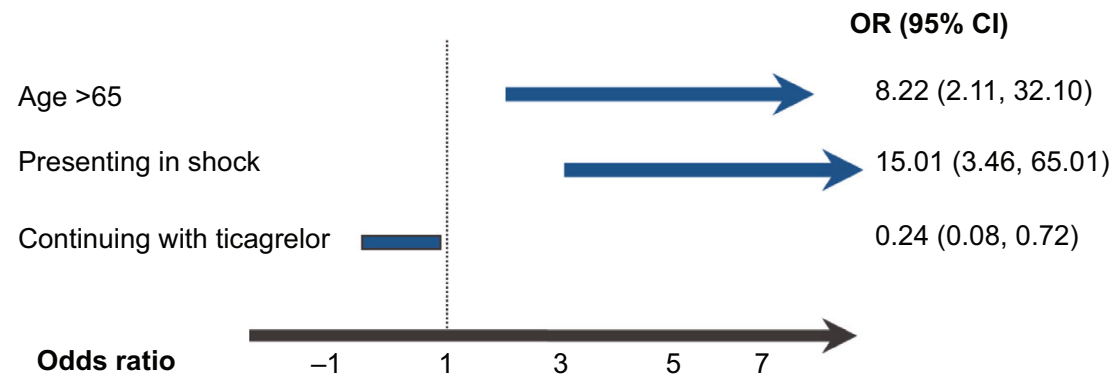

Figure 3 Multivariate predictors of having an event.

Notes: A test of the full model against a constant-only model was statistically significant, indicating that the predictors as a set reliably distinguished between those having an adverse event and those not having one [model $\chi^{2}(3)=39.84 ; P<0.00 I$ ]. Nagelkerke's $R^{2}$ of 0.36 indicated a moderate relationship between prediction and grouping. Prediction success overall was $94 \%$. The Wald criterion demonstrated that all three predictors contributed significantly to the model (age, $P<0.005 ;$ shock, $P<0.00 \mathrm{I}$; ticagrelor use, $P<0.05)$.

Abbreviations: $\mathrm{Cl}$, confidence interval; $\mathrm{OR}$, odds ratio. 
Table 3 Bleeding endpoints

\begin{tabular}{lllll}
\hline Endpoint & Entire cohort $(\mathbf{n}=\mathbf{2 2 7})$ & Ongoing ticagrelor & Stopped ticagrelor & $\boldsymbol{P}_{\text {-value* }}$ \\
\hline Any bleeding event & $28(12.3)$ & $18(10.0)$ & $10(21.3)$ & $<0.05$ \\
Major life-threatening bleeding & $6(2.6)$ & $3(1.7)$ & $3(6.4)$ & $<0.05$ \\
Major or minor bleeding & $22(9.7)$ & $15(8.3)$ & $7(14.9)$ & NS \\
\hline
\end{tabular}

Notes: Values are $\mathrm{n}(\%)$. Compared with ticagrelor ongoing therapy group.

growth has led to significant cultural expansion and an influx of immigrants in Saskatchewan, the predominant nonwhite population presenting with coronary artery disease are First Nations. Because the regulatory body that covers medications for First Nations is different than the provincial body, the regulatory body do not, to date, recognize ticagrelor as a medication that should be covered post-ACS or for high-risk unstable angina. This is the likely explanation for the early discontinuation rate of this medication observed in this group. As a result of this registry, discussions are currently underway to educate the regulatory bodies involved, with the hope of reversing this decision on the use of ticagrelor.

Somewhat surprisingly, age older than 65 years was not a protective factor for continuing with ticagrelor. In fact, the average age of patients continuing with ticagrelor was younger than that for those who stopped receiving ticagrelor. This may be explained by the increased prevalence of poor adherence to medications observed after retirement, often past the age of 65 years, ${ }^{27}$ and the welldocumented decreased likelihood for the elderly to receive evidence-based therapies compared with their younger counterparts. ${ }^{28,29}$ Other registries are concordant with the current study in identifying older age as a risk factor for poorer outcomes. ${ }^{30}$

Considered to be secondary to an increase in systemic adenosine concentrations, ticagrelor-induced dyspnea is a real phenomenon that has been well-described with an incidence ranging from $13 \%{ }^{1}$ to $25 \%{ }^{31}$ Although a subjective finding, literature suggests it does not lead to compromised pulmonary status and does not reduce the efficacy of ticagrelor. ${ }^{16}$ Although its severe form is rare $(<0.5 \%)$, duration of dyspnea can last less than 24 hours for some patients but can persist for weeks in others. ${ }^{16}$ However, in those with a previous history of asthma and chronic obstructive pulmonary disease, it can contribute to nonadherence. Ten patients in the current cohort complained of dyspnea, seven of whom, with sufficient and appropriate counseling, could likely have been encouraged to continue with the medication. Also linked to increased adenosine concentrations, ticagrelor causes more ventricular pauses compared with clopidogrel. Although this has not led to more clinical consequences in the literature, ${ }^{32}$ two patients in our cohort had to be switched to clopidogrel by their cardiologists because of symptomatic pauses.

The need for concomitant anticoagulation is an unexpected but not uncommon aspect of treating patients with coronary artery disease because of accompanying atrial fibrillation, or managing severe left ventricular dysfunction and/or clots after a large myocardial infarction. There are no published trials that have evaluated triple therapy incorporating ticagrelor in place of clopidogrel, but it is likely that major bleeding would be increased. ${ }^{33}$ Therefore, all efforts should be made to avoid ticagrelor in triple therapy, as was the practice of cardiologists in the current study with at least six of the patients in this cohort.

Although our cohort was not powered to look at clinical endpoints, our findings were consistent with the remainder of literature. Older age and presenting in cardiogenic shock were strong predictors of having an event. Although adherence has been linked to cardiovascular events, ${ }^{34}$ this registry is the first to show that prematurely stopping ticagrelor is associated with an event. Interestingly, even though this cohort likely represents a lower-risk population than that of PLATO (as 19\% did not even meet inclusion criteria), both event rate and bleeding rate were similar to that published for PLATO. This speaks to the higher event rate often observed in clinical registries compared with in clinical trials.

Two important points need to be emphasized with regard to bleeding and ticagrelor use in this registry. First, receiving ticagrelor within 24 hours after thrombolytic therapy was not associated with excess bleeding. As a pharmacoinvasive approach to patients after lytic therapy is a class $2 \mathrm{a}$ recommendation, this is an important real-world scenario of caring for our everyday postlytic patients. Goudevenos and colleagues have also reported this finding. ${ }^{35}$ This leads to the second observed point, that premature stoppage of ticagrelor was associated with increased bleeding. This may seem counterintuitive, as ticagrelor is a strong antiplatelet agent. However, our captured data may not be able to discern that the reason a patient stopped ticagrelor was because of a bleeding event. However, this may also be a real-life signal, as stopping ticagrelor prematurely leads to ischemic events, and we know these events are also a risk factor for bleeding events. Future exploratory studies are required to analyze this further. 


\section{Limitations}

Because of the novelty of this medication and its use, there are limited long-term follow-up data on this experience. However, as most of the events in the PLATO group occurred in the first 4 weeks, we are reassured that all patients alive at 4 weeks had a follow-up review. Adherence was defined by reviewing charts and patient self-report. No precise measures such as observed therapy or biological assays of ticagrelor, dyspnea scales, and/or continuous electrocardiography records for bradycardia were used. However, all charts were reviewed in person by the lead investigator. Inherent for all registry data, selection bias for both patients and physicians is at play. Importantly, the effect of the elevated cost of the ticagrelor compared with clopidogrel cannot be ascertained in this study because of the special circumstances of coverage offered by the AstraZeneca program. Although multiple nonPCI centers were involved, four interventional cardiologists made the majority of decisions regarding use of ticagrelor from one PCI facility. A larger sample size would have been preferable in allowing detection of other features contributing to adherence and/or physician behavior.

\section{Conclusion}

In this first description of ticagrelor adoption in a real-world setting, we found that a significant portion of ticagrelor usage is considered off-label. Because of both patient and physician factors, about $21 \%$ of patients started on ticagrelor were no longer taking it after a median follow-up of 21 days; this cohort represents a high-risk group for an event defined as death from vascular causes, myocardial infarction, or stroke. These findings suggest that both patient and physician education is necessary in improving adherence.

\section{Disclosure}

Dr Payam Dehghani has received research grants from AstraZeneca, the manufacturer of ticagrelor. The authors report no other conflicts of interest in this work.

\section{References}

1. Wallentin L, Becker RC, Budaj A, et al; PLATO Investigators. Ticagrelor versus clopidogrel in patients with acute coronary syndromes. $N$ Engl $J$ Med. 2009;361(11):1045-1057.

2. Bell AD, Roussin A, Cartier R, et al; Canadian Cardiovascular Society. The use of antiplatelet therapy in the outpatient setting: Canadian Cardiovascular Society guidelines. Can J Cardiol. 2011;27 Suppl A: S1-S59.

3. Hamm CW, Bassand JP, Agewall S, et al; ESC Committee for Practice Guidelines. ESC Guidelines for the management of acute coronary syndromes in patients presenting without persistent ST-segment elevation: The Task Force for the management of acute coronary syndromes (ACS) in patients presenting without persistent ST-segment elevation of the European Society of Cardiology (ESC). Eur Heart J. 2011;32(23):2999-3054.
4. Steg PG, James SK, Atar D, et al; Task Force on the management of ST-segment elevation acute myocardial infarction of the European Society of Cardiology (ESC). ESC Guidelines for the management of acute myocardial infarction in patients presenting with ST-segment elevation. Eur Heart J. 2012;33(20):2569-2619.

5. Jneid H, Anderson JL, Wright RS, et al; 2012 Writing Committee Members; American College of Cardiology Foundation; American Heart Association Task Force on Practice Guidelines. 2012 ACCF/ AHA focused update of the guideline for the management of patients with unstable angina/Non-ST-elevation myocardial infarction (updating the 2007 guideline and replacing the 2011 focused update): a report of the American College of Cardiology Foundation/American Heart Association Task Force on practice guidelines. Circulation. 2012;126(7): 875-910.

6. O'Gara PT, Kushner FG, Ascheim DD, et al; American College of Emergency Physicians; Society for Cardiovascular Angiography and Interventions. $2013 \mathrm{ACCF} / \mathrm{AHA}$ guideline for the management of ST-elevation myocardial infarction: a report of the American College of Cardiology Foundation/American Heart Association Task Force on Practice Guidelines. J Am Coll Cardiol. 2013;61(4): e78-e140.

7. Goodman SG, Huang W, Yan AT, et al; Expanded Global Registry of Acute Coronary Events (GRACE2) Investigators. The expanded Global Registry of Acute Coronary Events: baseline characteristics, management practices, and hospital outcomes of patients with acute coronary syndromes. Am Heart J. 2009;158(2):193-201.

8. Ackman ML, Graham MM, Hui C, Tsuyuki RT. Effect of a prior authorization process on antiplatelet therapy and outcomes in patients prescribed clopidogrel following coronary stenting. Can J Cardiol. 2006;22(14):1205-1208.

9. Sheehy O, LeLorier J, Rinfret S. Restrictive access to clopidogrel and mortality following coronary stent implantation. CMAJ. 2008;178(4): 413-420.

10. Jackevicius CA, Li P, Tu JV. Prevalence, predictors, and outcomes of primary nonadherence after acute myocardial infarction. Circulation. 2008;117(8):1028-1036.

11. Yancy CW, Fowler MB, Colucci WS, et al; US Carvedilol Heart Failure Study Group. Race and the response to adrenergic blockade with carvedilol in patients with chronic heart failure. N Engl J Med. 2001;344(18): 1358-1365.

12. Thygesen K, Alpert JS, White HD; Joint ESC/ACCF/AHA/WHF Task Force for the Redefinition of Myocardial Infarction. Universal definition of myocardial infarction. J Am Coll Cardiol. 2007;50(22): 2173-2195.

13. Cutlip DE, Windecker S, Mehran R, et al; Academic Research Consortium. Clinical end points in coronary stent trials: a case for standardized definitions. Circulation. 2007;115(17):2344-2351.

14. Montalescot G, Lassen JF, Hamm CW, et al. Ambulance or incatheterization laboratory administration of ticagrelor for primary percutaneous coronary intervention for ST-segment elevation myocardial infarction: rationale and design of the randomized, double-blind Administration of Ticagrelor in the cath Lab or in the Ambulance for New ST elevation myocardial Infarction to open the Coronary artery (ATLANTIC) study. Am Heart J. 2013;165(4):515-522.

15. Cannon CP, Harrington RA, James S, et al; PLATelet inhibition and patient Outcomes Investigators. Comparison of ticagrelor with clopidogrel in patients with a planned invasive strategy for acute coronary syndromes (PLATO): a randomised double-blind study. Lancet. 2010; 375(9711):283-293.

16. Storey RF, Becker RC, Harrington RA, et al. Characterization of dyspnoea in PLATO study patients treated with ticagrelor or clopidogrel and its association with clinical outcomes. Eur Heart J. 2011;32(23): 2945-2953.

17. James S, Budaj A, Aylward P, et al. Ticagrelor versus clopidogrel in acute coronary syndromes in relation to renal function: results from the Platelet Inhibition and Patient Outcomes (PLATO) trial. Circulation. 2010;122(11):1056-1067. 
18. James S, Angiolillo DJ, Cornel JH, et al; PLATO Study Group. Ticagrelor vs clopidogrel in patients with acute coronary syndromes and diabetes: a substudy from the PLATelet inhibition and patient Outcomes (PLATO) trial. Eur Heart J. 2010;31(24):3006-3016.

19. Husted S, James S, Becker RC, et al; PLATO study group. Ticagrelor versus clopidogrel in elderly patients with acute coronary syndromes: a substudy from the prospective randomized PLATelet inhibition and patient Outcomes (PLATO) trial. Circ Cardiovasc Qual Outcomes. 2012;5(5):680-688.

20. James SK, Storey RF, Khurmi NS, et al; PLATO Study Group. Ticagrelor versus clopidogrel in patients with acute coronary syndromes and a history of stroke or transient ischemic attack. Circulation. 2012;125(23): 2914-2921.

21. Held C, Asenblad N, Bassand JP, et al. Ticagrelor versus clopidogrel in patients with acute coronary syndromes undergoing coronary artery bypass surgery: results from the PLATO (Platelet Inhibition and Patient Outcomes) trial. J Am Coll Cardiol. 2011;57(6):672-684.

22. Wallentin L, James S, Storey RF, et al; PLATO investigators. Effect of CYP2C19 and ABCB1 single nucleotide polymorphisms on outcomes of treatment with ticagrelor versus clopidogrel for acute coronary syndromes: a genetic substudy of the PLATO trial. Lancet. 2010;376(9749): 1320-1328.

23. Kohli P, Wallentin L, Reyes E, et al. Reduction in first and recurrent cardiovascular events with ticagrelor compared with clopidogrel in the PLATO Study. Circulation. 2013;127(6):673-680.

24. Nikolic E, Janzon M, Hauch O, Wallentin L, Henriksson M; PLATO Health Economic Substudy Group. Cost-effectiveness of treating acute coronary syndrome patients with ticagrelor for 12 months: results from the PLATO study. Eur Heart J. 2013;34(3):220-228.

25. Alexopoulos D, Goudevenos JA, Xanthopoulou I, et al; GRAPE Investigators. Implementation of contemporary oral antiplatelet treatment guidelines in patients with acute coronary syndrome undergoing percutaneous coronary intervention: a report from the GReek AntiPlatelet rEgistry (GRAPE). Int J Cardiol. 2013;168(6):5329-5335.

26. Goudevenos J, Ntalas I, Xanthopoulou I, Kalantzi K, Pipilis A, Alexopoulos D. Use of ticagrelor in patients with ST-elevation myocardial infarction undergoing thrombolysis. J Thromb Thrombolysis. 2014;37(3):356-357.

27. Kivimäki M, Batty GD, Hamer M, et al. Influence of retirement on nonadherence to medication for hypertension and diabetes. CMAJ. 2013;185(17):E784-E790.
28. Alexander KP, Newby LK, Armstrong PW, et al; American Heart Association Council on Clinical Cardiology; Society of Geriatric Cardiology. Acute coronary care in the elderly, part II: ST-segment-elevation myocardial infarction: a scientific statement for healthcare professionals from the American Heart Association Council on Clinical Cardiology: in collaboration with the Society of Geriatric Cardiology. Circulation. 2007;115(19):2570-2589.

29. Alexander KP, Newby LK, Cannon CP, et al; American Heart Association Council on Clinical Cardiology; Society of Geriatric Cardiology. Acute coronary care in the elderly, part I: Non-ST-segment-elevation acute coronary syndromes: a scientific statement for healthcare professionals from the American Heart Association Council on Clinical Cardiology: in collaboration with the Society of Geriatric Cardiology. Circulation. 2007;115(19):2549-2569.

30. Alexander KP, Roe MT, Chen AY, et al; CRUSADE Investigators. Evolution in cardiovascular care for elderly patients with non-ST-segment elevation acute coronary syndromes: results from the CRUSADE National Quality Improvement Initiative. J Am Coll Cardiol. 2005;46(8):1479-1487.

31. Gurbel PA, Bliden KP, Butler K, et al. Randomized double-blind assessment of the ONSET and OFFSET of the antiplatelet effects of ticagrelor versus clopidogrel in patients with stable coronary artery disease: the ONSET/OFFSET study. Circulation. 2009;120(25):2577-2585.

32. Scirica BM, Cannon CP, Emanuelsson H, et al; PLATO Investigators The incidence of bradyarrhythmias and clinical bradyarrhythmic events in patients with acute coronary syndromes treated with ticagrelor or clopidogrel in the PLATO (Platelet Inhibition and Patient Outcomes) trial: results of the continuous electrocardiographic assessment substudy. J Am Coll Cardiol. 2011;57(19):1908-1916.

33. Cairns JA, McMurtry MS. Oral antithrombotic therapy in atrial fibrillation associated with acute or chronic coronary artery disease. Can J Cardiol. 2013;29(7)(Suppl):S60-S70.

34. Rodriguez F, Cannon CP, Steg PG, et al; REACH Registry Investigators. Predictors of long-term adherence to evidence-based cardiovascular disease medications in outpatients with stable atherothrombotic disease: findings from the REACH Registry. Clin Cardiol. 2013;36(12):721-727.

35. Goudevenos J, Ntalas I, Xanthopoulou I, Kalantzi K, Pipilis A, Alexopoulos D. Use of ticagrelor in patients with ST-elevation myocardial infarction undergoing thrombolysis. J Thromb Thrombolysis. 2014;37(3):356-357.
Patient Preference and Adherence

\section{Publish your work in this journal}

Patient Preference and Adherence is an international, peer-reviewed, open access journal that focuses on the growing importance of patient preference and adherence throughout the therapeutic continuum. Patient satisfaction, acceptability, quality of life, compliance, persistence and their role in developing new therapeutic modalities and compounds to optimize

\section{Dovepress}

clinical outcomes for existing disease states are major areas of interest for the journal. This journal has been accepted for indexing on PubMed Central. The manuscript management system is completely online and includes a very quick and fair peer-review system, which is all easy to use. Visit http://www. dovepress.com/testimonials.php to read real quotes from published authors. 